\title{
Total quality management at the Walter C Mackenzie Health Sciences Centre: Positive experience of the Division of Gastroenterology
}

\author{
ABR THOMSON MD PhD FRCPC FACP FRS FACC, L WALZ CCHRAC, K SUTHERLAND BScN MA
}

$\mathrm{O}$ NTHE JOURNEY TOWARDS IMPLEMENTATION OF 'TOTAL quality management' at the University Hospital in Edmonton, Alberta, we began with a vision of what the organization will evolve into and a commitment to that vision. This vision is captured in our 'reason for being statement': leadership in health care - caring, teaching, discovering. We identified three 'core values' central to all our employees and team players: respect, partnership and continuous improvement'. The reason for being and the core values were formulated from the 'mission statement': "The University of Alberta Hospital is committed to providing exemplary patient care and education in an atmosphere of compassion and scholarly inquiry while preserving the dignity and rights of patients and their families". Beginning with a shared vision, training and coaching classes were provided. Medical quality improvement (MQI) was, and remains central to, this commitment to excellence.

With the rising demands on the increasingly limited availability of health care funds, we became concerned and got involved in the process of attempting to improve the quality of our gastroenterological services provided at the University of Alberta Hospital, at the Walter Mackenzie Health Sciences Centre (WMHSC).

Nutrition and Metabolism Research Group, Division of Gastroenterology, Department of Medicine, University of Alberta, Edmonton, Alberta

Correspondence and reprints: Dr ABR Thomson, 519 Robert Newton Research Building, University of Alberta, Edmonton, Alberta T6G 2C2. Telephone (403) 492-6490, Fax (403) $492-7964$
Quality planning involves four components: identifying the customers of a particular process; measuring customer needs and expectations of the process and its outputs; designing a product or service responsive to their needs; and developing the process capable of producing the desired outcome. Our approach was to become partners in the process of change designed to improve cost efficiency, clinical outcome and quality of care.

The members of the Division of Gastroenterology volunteered to be one of three groups (gastroenterology, general surgery and pediatrics) that would initially participate in the $\mathrm{MQI}$ process at our institution (we do not use the quality assurance program at the WMHSC). The groups met to establish guidelines for accepted standards of care of gastrointestinal (GI) in-patients. With a prediscussed consensus-derived document, specially trained nursing staff reviewed the GI in-patient charts on a regular basis and prepared a monthly report. A designated member of the GI Division was our 'MQI person', a peet-reviewer. We identified management objectives, screening and a series of evaluation criteria. These reports, given to members of the Division at regularly scheduled meetings, were numbered documents which were circulated, discussed and then returned to our MQI person to maintain confidentiality. Any deviations from standard practice were discussed at length, and recommendations were made as to how the level of care could be improved in the future. There was an initial period of suspicion and discomfort, but over time and with the maintenance of confidentiality regarding the specific physicians involved on the monthly ward rotations, the sense of participation improved and all members 'bought into' the importance of this process. This 
TABLE 1

Number of patients in major diagnostic categories in the gastrointestinal ward at the Walter Mackenzie Health Sciences Centre

\begin{tabular}{lcc}
\hline & $\begin{array}{c}1990-91 \\
\text { number (\%*) }\end{array}$ & $\begin{array}{c}1991-92 \\
\text { number (\%*) }\end{array}$ \\
\hline Inflammatory bowel disease & $65(28)$ & $75(30)$ \\
Gastrointestinal bleeding & $38(16)$ & $50(20)$ \\
Irritable bowel syndrome & $39(17)$ & $31(12)$ \\
Peptic ulcer disease & $13(6)$ & $28(11)$ \\
Chronic liver disease & $34(15)$ & $25(10)$ \\
Gastroesophageal reflux disease & $7(3)$ & $12(5)$ \\
Bowel obstruction & $6(2)$ & $11(4)$ \\
Pancreatitis & $13(6)$ & $11(4)$ \\
Gastritis & $16(7)$ & $9(4)$ \\
\hline
\end{tabular}

The approximate percentages are based on the above figures, but please note that there was a number of occasional diagnoses not represented here

\section{TABLE 2}

Average length of stay by gastrointestinal diagnosis and institution in 1991

\begin{tabular}{lrrrrrr}
\hline Institution & CD & \multicolumn{1}{c}{ UC } & GERD & Pancreatitis & GI bleed & Mean \\
\hline 1 & 14.2 & 16.3 & 7.3 & 9.8 & 5.0 & 11.2 \\
2 & 16.0 & 16.0 & 10.0 & 16.0 & 7.0 & 12.3 \\
3 & 11.0 & 11.4 & 6.0 & 9.8 & 15.4 & 7.7 \\
4 & 12.8 & 11.1 & 11.7 & 13.6 & 16.1 & 11.1 \\
5 & 15.2 & 11.9 & 5.5 & 10.9 & 7.9 & 9.5 \\
6 & 22.1 & 16.3 & 7.5 & 21.6 & 8.6 & 10.1 \\
\hline
\end{tabular}

The name of the institution has been blinded to maintain confidentiality. $C D$ Crohn's disease; GERD Gastroesophageal reflux disease; GI bleed Gastrointestinal bleeding: UC Ulcerative colitis

monthly MQI process supplemented a monthly management unit review of all deaths that occurred on the ward service. MQI, with its concurrent review, identifies more than $85 \%$ of adverse occurrences, in contrast to the much lower sensitivity of the traditional retrospective review. Furthermore, review takes place within the memory of the caregivers, and the possibility for learning and reinforcement is enhanced. Over a period of six months, the number of MQI areas of concern (such as adverse occurrences or failure to meet a preset standard of practice) gradually diminished. Examining and simplifying processes to prevent waste, rework and inefficiencies was accomplished through education about the quality improvement process. Nursing and physician acceptance of this process was generally satisfactory.

Over the process of the MQI review, we also began to review data on our length of study to see if this was altered by the MQI process. The first step was to identify the major diagnostic categories on our GI ward (Table 1). In 1990-91 and $1991-92$, over $80 \%$ of our in-patients had one of five diagnoses: inflammatory bowel disease (IBD), GI bleeding, irritable bowel syndrome, peptic ulcer disease and chronic liver disease. We solicited and received the helpful cooperation of five other major Canadian teaching hospitals. The average length of study for the five institutions plus our own

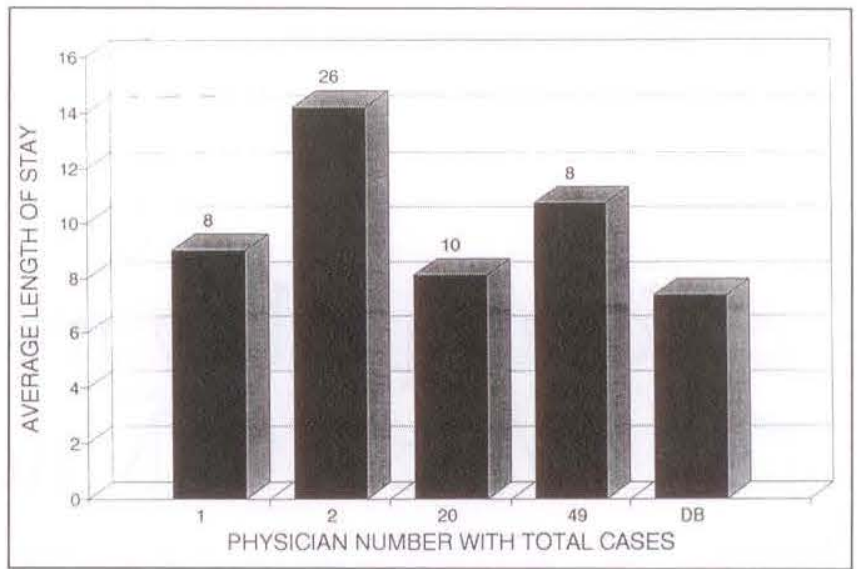

Figure 1) Variability between physicians of average length of stay of patients with inflammatory bowel disease (fiscal year 1990/91). DB Database from the Hospital Medical Record Institute

were tabulated by institution and by patient discharge diagnosis (Table 2). The length of study varied from 7.7 to 12.3 days. This spread of 4.6 days was explained in part by diseasespecific differences; for example, for gastroesophageal reflux disease (GERD), the length of study varied from 5.5 to 11.7 days and the average length of study for GI bleeding varied widely (Table 2). Indeed, even within one institution (Edmonton), there was wide variability between physicians in average length of study for patients with Crohn's disease and ulcerative colitis (Figure 1). This information does not provide any understanding of the reason for these differences, but simply represents the variability in the Canadian experience. With a sample of only six institutions, no judgement is possible - or implied - as to the appropriateness of this wide variation in length of study. But once we note the differences, we can work to establish their basis and perhaps we may further improve, and shorten, in-patient care.

One way of attempting to compare one institution fairly with another is to look at resource-intensity weight (RIW) of typical cases, and to compare the expected with the actual average length of study. These data were collected for April to December 1991 from 30 teaching hospitals from Newfoundland to British Columbia. The actual average length of study for gastroenterology was 7.2 days, range 6.2 to 10.0 . However, the average RIW for typical cases in these institutions range from 2.367 to 0.938 (is not 'fair' to compare average length of study without taking into account the RIW). If one compares the difference between the expected and the actual length of study, it can be appreciated whether an institution and their gastroenterology team is a little under or a little over what might be expected based on the RIW (Table $3)$. When this is taken into account, some hospitals are as much as 2.5 days over, and others are as many as 2.5 days under, the expected length of stay based on the RIW of their patients (complete data not shown, but available upon request).

A further reason why it is unreasonable to compare the average length of study between institutions directly (Table 2 ) is because some institutions have a much higher percent- 
TABLE 3

Hospital Medical Records Institute comparison of hospital activity

\begin{tabular}{|c|c|c|c|c|c|}
\hline \multirow[b]{2}{*}{ Institution } & \multicolumn{4}{|c|}{ Typical } & \multirow[b]{2}{*}{$\%$ typical } \\
\hline & $\begin{array}{l}\text { Average resource- } \\
\text { intensity weight }\end{array}$ & $\begin{array}{l}\text { Actual average } \\
\text { length of stay }\end{array}$ & $\begin{array}{l}\text { Expected average } \\
\text { length of stay }\end{array}$ & $\begin{array}{l}\text { Difference between } \\
\text { expected and actual }\end{array}$ & \\
\hline 7 & 1.209 & 9.6 & 7.1 & +2.5 & 60.1 \\
\hline 8 & 1.433 & 7.7 & 7.8 & -0.1 & 87.8 \\
\hline 9 & 1.362 & 7.8 & 7.6 & +0.2 & 53.4 \\
\hline 10 & 1.136 & 4.1 & 6.6 & -2.5 & 71.0 \\
\hline
\end{tabular}

The name of the institution has been blinded to maintain confidentiality

age of 'atypical' patients, and the acuity of this case mix might, but does not necessarily, influence the length of study. For example, the average length of study for the WMHSC is 9.5 days compared with 6.9 for the Foothills Hospital in Calgary, yet the Edmonton RIW was 1.652 compared with 1.364 for Calgary. Indeed, when comparing atypical patients, the University of Alberta had an average RIW of 3.483 versus 2.270 for the Foothills, and in typical patients with average RIWs of 1.075 and 1.214 , respectively, the difference between the actual and expected length of study was again 1.3 days for the WMHSC versus 0.8 days for the Foothills Hospital. The point, therefore, is that one can roughly say where an institution fits into the general Canadian picture, but the acuity of the cases needs to be determined and one needs to use some benchmark for comparison before suggesting that an apparently low length of study was due to physician or institution inefficiency, or was due to some other factor. For example, if an institution has a major mix of transplantation cases, this may greatly impact their length of study.

Within a given institution, another way to determine whether the length of study reflects the disease severity is to use the refined diagnostic related group (RDRG). RDRGs are only used in Alberta. With an RDRG description of 0 , the length of study at the WMHSC was 5.8 days, increasing to 9.8 and 8.1 days for RDRG of ' 1 ' and ' 2 ', respectively. This provides no information on outcome, but simply reflects the fact that our sicker patients tend to be in hospital longer. Another reflection on factors which may influence length of study is the percentage of patients admitted to a gastroenterology service via the emergency room. These percentages vary widely, from $87 \%$ at the Vancouver General Hospital and St Mary's Hospital in Montreal to a low of $24 \%$ at the University Hospital in Saskatoon. However, this does not necessarily indicate that patients coming by way of the emergency room were 'sicker'; this may simply reflect patient transfer processes or admitting practices.

From 1989 until the end of 1991, the average length of study at the WMHSC only fell from $9.79 \pm 3.79$ (mean \pm SD) to $9.46 \pm 3.17$ days. When considering matched length of study, the improvement was more apparent, $8.9 \pm 3.4$ to $7.0 \pm 2.2$ days (Figure 2). Over the interval of our MQI program, therefore, the average length of study fell $21 \%$. Of perhaps equal interest was the decline in the between-physician variability, with a fall in the coefficient of variation from 38.7 to $33.5 \%$ for

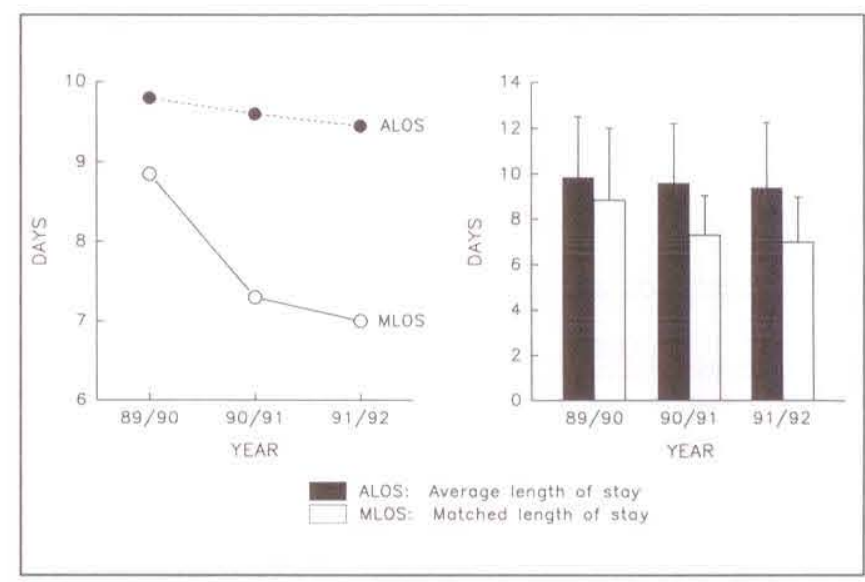

Figure 2) Average and matched length of stay

average length of study, and from 34.8 to $30.9 \%$ for matched length of study. None of these differences, however, was statistically significant, but differences represent a meaningful trend. We have a designated gastroenterology ward, with an average of over $85 \%$ occupancy, and the number of beds available for admission did not change during that interval, yet the number of patients fluctuated. In 1989-90, our ward service cared for 657 patients, falling to 533 in 1990-91 and rising to 576 in 1991-92. We note with interest the decline in average and matched length of study, and the decline in variability between gastroenterologists concerning individual length of study; these improvements, although not statistically significant and although not associated with a hoped-for increase in patient-admissions as a result of improved efficiency and reduced length of study, nonetheless occurred in the early days of our MQI program. Time, patience and enthusiasm will permit us to determine whether the major time, financial and emotional commitments to MQI will lead to improved outcome. We sincerely hope so.

Another important measure of $\mathrm{MQI}$ is the process of identifying the patient resource consumption profile. This method determines patient-specific costing, allowing us to examine the manner in which the peer-review process identifies certain aspects of practice behaviour which is outside the group norm, and institutes a process by which this can be reviewed, reassessed and measured. Within one case mix group (esophagitis, gastroenteritis and miscellaneous diges- 


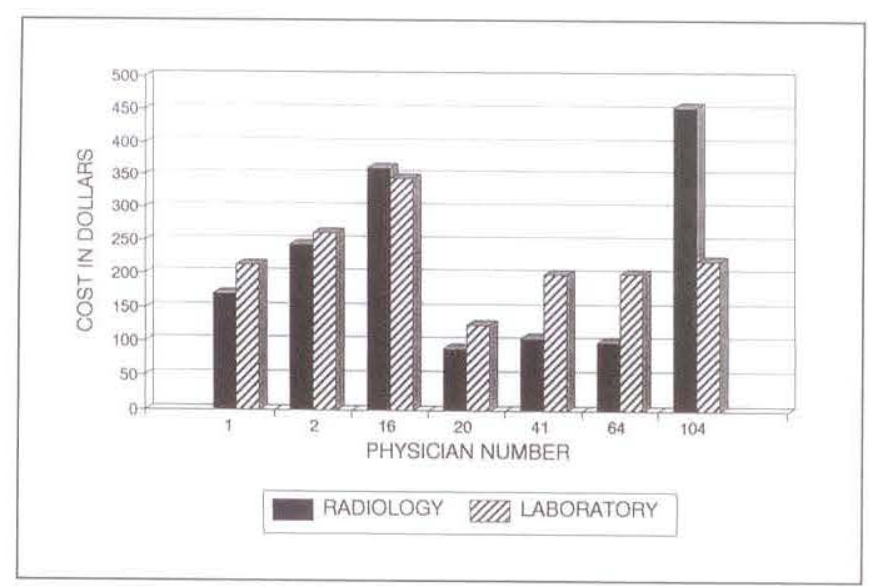

Figure 3a) Variability between physicians in cost of radiology and laboratory tests in patients with esophagitis, gastroenteritis and miscellaneous digestive diseases, younger than 70 years with complications or comorbid conditions, older than 70 years without complications or comorbid conditions

tive diseases, younger than 70 years with complications or comorbid conditions, older than 70 years without complications or comorbid conditions) for seven gastroenterologists at WMHSC, there was more than a fourfold spread in the average cost per patient of radiological and laboratory services (Figure 3a). This was also seen within a single diagnostic group of inflammatory bowel diseases, Crohn's disease and ulcerative colitis (Figure $3 \mathrm{~b}$ ). The explanation for this greatly variable practice pattern is unknown, and must be addressed in future MQI deliberations. This likely represents an opportunity to save dollars and to assess outcomes.

Is the MQI simply a cost-saving measure? Yes and no. Yes, cost-saving is one of the clear benefits of an MQI program, but there are many others, including the possibility of greater future hospital patient through-put, greater sense of professional pride and possibly improved patient outcome. There is also the possibility of reducing unnecessary or duplicated

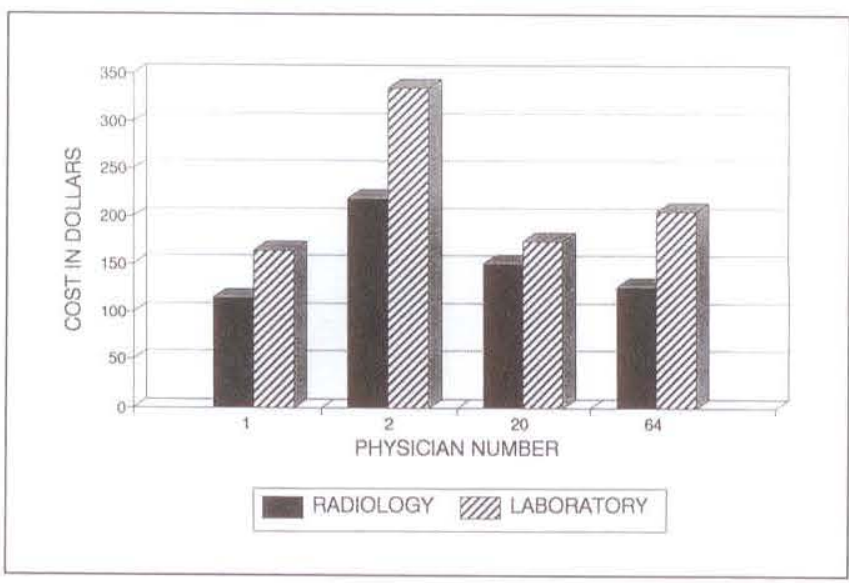

Figure 3b) Variability between physicians of cost of radiology and laboratory tests in patients with inflammatory bowel disease

diagnostic tests or inappropriate therapy. The process needs to be assessed as it evolves, to assure the quality of the quality assessors. This is the way of the future - all aboard?!

ACKNOWLEDGEMENTS: We thank the personnel in the Medical Records Departments of six teaching hospitals for their cooperation and support: Victoria General Hospital (Halifax), University of Western Ontario (London), Hotel Dieu Hospital (Kingston), Kingston General Hospital (Kingston), Walter Mackenzie Health Sciences Centre (Edmonton) and University Hospital (Vancouver). We also thank Dr RH Wensel, VP Medical, WMHSC, and the members of the Division of Gastroenterology, WMHSC and University of Alberta: Drs Vince Bain, Eoin Lalor, Richard Fedorak, Dan Sadowski, Dick Sherbaniuk, Eric Semlacher and Bruce Yacyshyn.

\section{BIBLIOGRAPHY}

Goonan KJ, Jordan HS. Is QA antiquated, or was it at the right place at the wrong time? ORB 1992;November:372-9. 


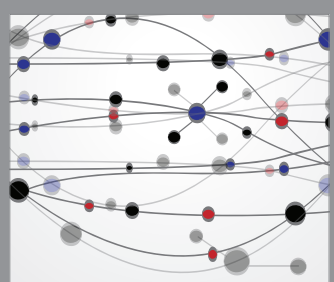

The Scientific World Journal
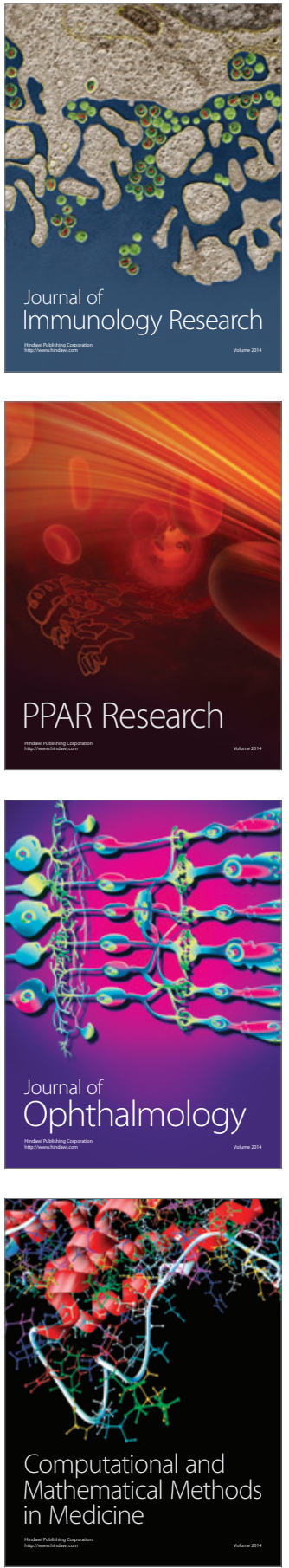

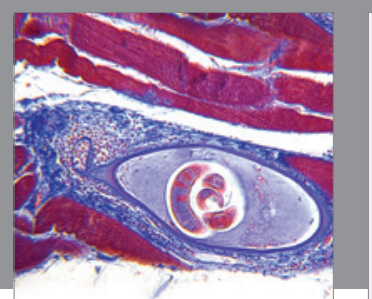

Gastroenterology Research and Practice

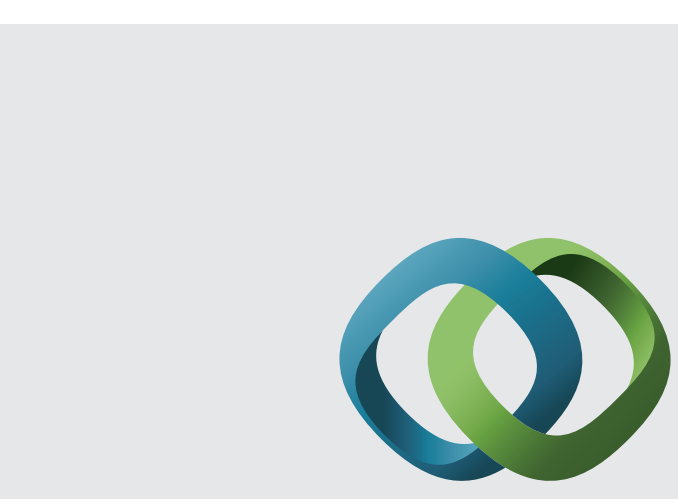

\section{Hindawi}

Submit your manuscripts at

http://www.hindawi.com
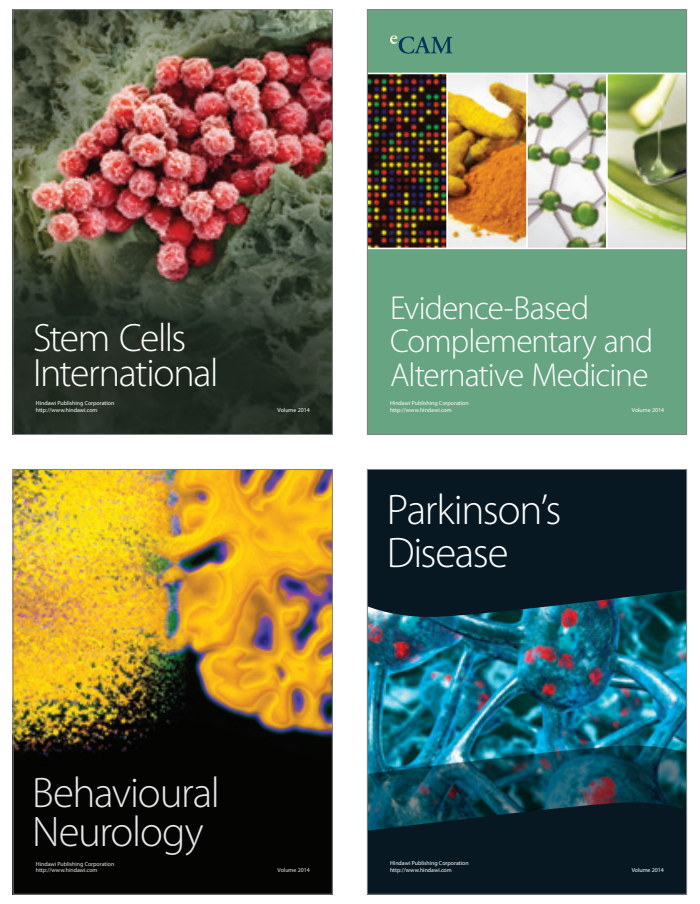
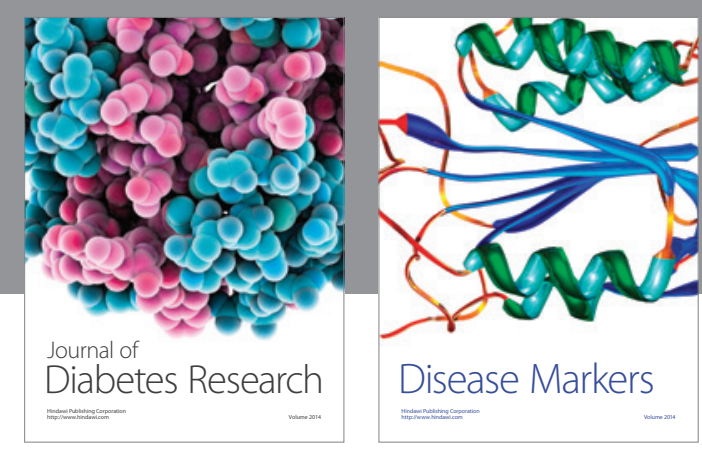

Disease Markers
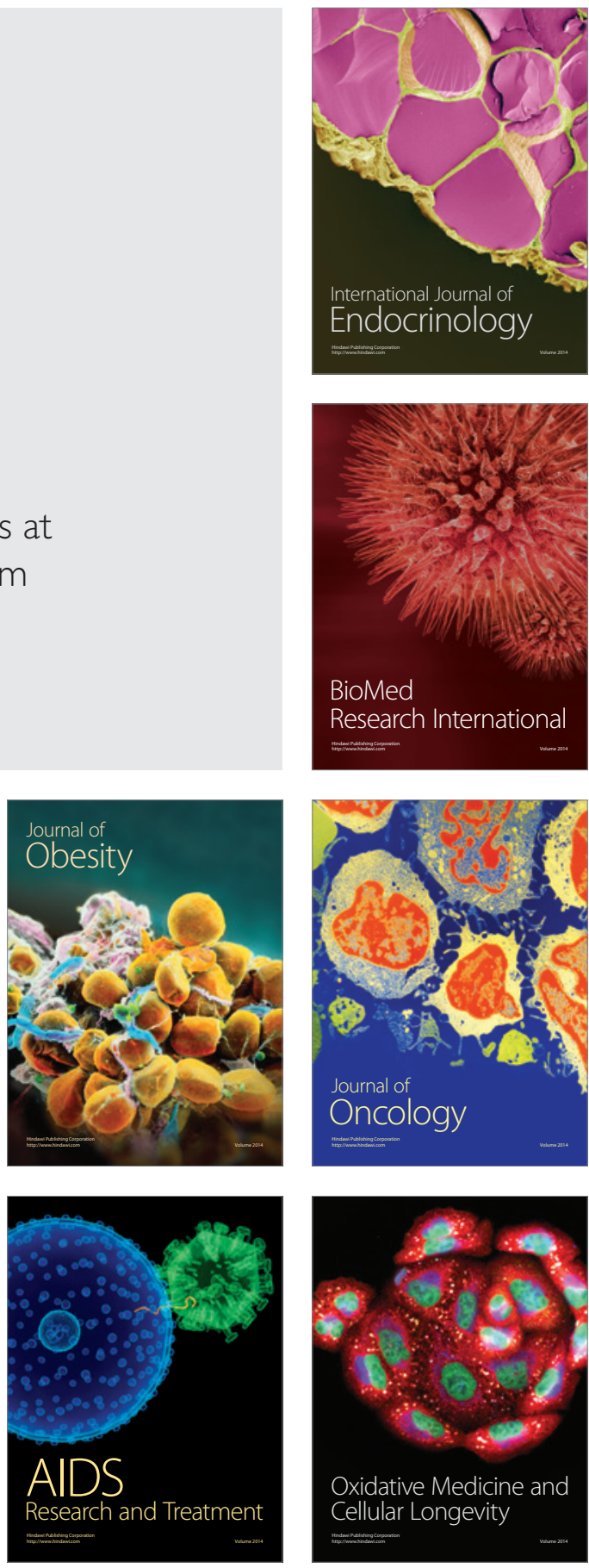